\title{
Drugs that lower the seizure threshold
}

\author{
Andrew W Hitchings \\ Senior lecturer in clinical pharmacology and honorary consultant in neuro-intensive care \\ St George's, University of London and St George's University Hospitals NHS Foundation Trust \\ Cranmer Terrace, London, SW17 ORE \\ Email ahitchin@sgul.ac.uk
}

\section{Summary}

Drugs with potential to lower the seizure threshold are numerous and diverse. Whether they contribute to clinically overt seizures depends on the dosage in which they are taken, the time-course of their effects, and the susceptibility of the patient. Crucially, however, their contribution to seizure risk is potentially modifiable.

\section{Seizures and the seizure threshold}

\section{Terminology}

A seizure is the clinical manifestation of abnormal, excessive or synchronous neuronal firing in the brain. ${ }^{1}$ The clinical features of seizures may include abnormalities of consciousness, movement, sensation, behaviour and autonomic function. Epilepsy is the enduring tendency to experience seizures.

The seizure threshold describes the minimum intensity of a stimulus required to induce a seizure. It is clinically evident in the context of electroconvulsive therapy, but is otherwise primarily an experimental phenomenon, in which seizures are induced by electrical or chemical stimuli (e.g. with pentylenetetrazole). It is often evaluated during drug development to quantify the extent to which a drug prevents seizures (if this is the intended therapeutic effect) or induces them (as an unwanted effect). As a broader concept, it is useful in clinical practice as a framework to help understand the complex interplay between the patient, their medicines, and their risk of seizures.

\section{Pathophysiology and pharmacology}

Seizures occur when there is an excess of excitatory activity relative to inhibitory activity. Glutamate and gamma-aminobutyric acid (GABA) are, respectively, the principle excitatory and inhibitory neurotransmitters in the central nervous system (CNS). Glutamate acts via N-methyl-D-aspartate (NMDA), alpha-amino-3-hydroxy-5-methyl-4-isoxazoleproprionic acid (AMPA) and kainite receptors to cause an influx of sodium and calcium ions, favouring depolarisation. GABA acts primarily through $G_{A B}$ receptors to cause an influx of chloride ions, inducing hyperpolarisation. The mechanisms of action of antiepileptic drugs are not universally understood, but include inference with sodium (e.g. phenytoin, carbamazepine, lamotrigine) and calcium channels (e.g. ethosuxamide); enhancing the effects of GABA 
(e.g. benzodiazepines); antagonising glutamate at AMPA receptors (e.g. perampanel); and a combination of these effects (e.g. valproate). Drugs with the opposite effects may induce seizures.

The propensity of a drug to induce seizures depends on its effects on neurotransmission and their timecourse (e.g. whether it increases seizure risk during use or on withdrawal), the concentration of drug reaching the brain, and the susceptibility of the individual patient. Susceptibility factors include previous seizures, structural or functional brain abnormalities, and concurrent drug use. In the face of such complexity, it is rare that seizures can be ascribed primarily to the effects of a drug (i.e. 'drug-induced seizures'). Commonly, however, drugs contribute to a shift in excitatory/inhibitory balance which, in that individual at that time, leads to a seizure. In this respect, it is generally more helpful to regard such drugs as having lowered the seizure threshold, rather than having incited seizures per se.

Many drugs have indirect effects on the seizure threshold, for example by inducing hypoglycaemia, electrolyte disturbances or respiratory depression, or by interacting with antiepileptic therapy. However, this review will concentrate on drugs that lower the seizure threshold via direct effects in the brain.

\section{Specific drugs}

\section{Antimicrobials}

\section{Beta-lactams}

Beta-lactam antibiotics, including penicillins, cephalosporins and carbapenems, interact with the $G A B A_{A}$ receptor to interfere with the inhibitory effects of GABA in a concentration-dependent manner. ${ }^{2}$ Correspondingly, they have dose-dependent effects on the seizure threshold. ${ }^{3,4}$ However, the CNS penetration of penicillins and cephalosporins is relatively low. ${ }^{5}$ As such, most reports of seizures associated with these agents emerge from their use in high doses (often in the treatment of CNS infections) or in renal failure. ${ }^{6}$ Carbapenems more readily penetrate the CNS and their use is associated with an increased seizure risk compared with non-carbapenem antibiotics. ${ }^{7}$ Among the carbapenems, imipenem is generally thought to have the highest risk. However, this may be because studies conducted on the newer agents (meropenem, ertapenem and doripenem), informed by earlier experience with imipenem, generally excluded patients with a history of seizures. Head-to-head comparisons of imipenem and meropenem do not reveal significant differences in seizure risk. ${ }^{7}$

In addition to their direct effects on the seizure threshold, carbapenems have an interaction with valproate which is sufficiently significant to deserve special mention. It is most readily observed with meropenem, which is associated with a consistent and substantial reduction in serum valproate concentration, in some cases precipitating seizures. ${ }^{8,9}$ This interaction occurs whether valproate is administered enterally or intravenously, and its onset and offset are rapid (within days). Its mechanism is uncertain, but its time-course and consistency between routes of administration suggests enhanced elimination or redistribution, possibly into red blood cells, as possible candidates. ${ }^{9}$ 


\section{Isoniazid}

The antituberculous agent isoniazid inhibits pyridoxine phosphokinase, the enzyme which converts pyridoxine to its active form, pyridoxal-5-phosphate. Pyridoxal-5-phosphate is an essential cofactor in the synthesis of GABA from glutamate. The resulting fall in inhibitory activity and rise in excitatory activity leads to a dose-dependent reduction in the seizure threshold. Isoniazid toxicity is characterised by a triad of altered mental status, metabolic acidosis and refractory seizures. Treatment with pyridoxine and a benzodiazepine usually results in prompt seizure termination.

\section{Antimalarials}

The antimalarial agents mefloquine and chloroquine can precipitate seizures in people with epilepsy, and have also been associated with seizures in healthy individuals. ${ }^{10,11}$ Depending on resistance patterns, doxycycline and atovaquone/proguanil (Malarone ${ }^{\circledR}$ ) may be suitable alternatives for malarial prophylaxis in patients at risk of seizures. The half-life of doxycycline is reduced in patients taking carbamazepine or phenytoin; a higher dosage (100 mg twice daily) should therefore be used. ${ }^{12}$

\section{Other antimicrobials}

Fluoroquinolones have comparatively high CNS penetration ${ }^{5}$ and they may inhibit the GABA receptor. $^{13}$ Seizures are rare but have been reported, particularly with ciprofloxacin in the context of other susceptibility factors. ${ }^{6}$ Macrolides, tetracyclines, aminoglycosides and glycopeptides have not been associated with seizures. ${ }^{6}$

\section{Analgesics}

\section{Opioid analgesics}

Opioids are associated with diverse effects on the seizure threshold. These vary between drugs, and within drugs according to dosage, experimental model and susceptibility factors. For example, morphine potentiates chemically-induced seizures but protects against electrically-induced seizures ${ }^{14}$; the clinical implications of this are uncertain. Moreover, the relationships between dosage and seizure threshold are complex. Experimentally, morphine has anticonvulsant effects at low doses but is pro-convulsant at high doses, whereas this pattern is reversed for fentanyl and pethidine. ${ }^{15}$

Tramadol is commonly associated with seizures in overdose, ${ }^{16}$ and also during therapeutic use. Its supplementary effects in inhibiting noradrenaline and serotonin reuptake, not shared by other opioids, are often cited as an explanation for this. However, in animal models, tramadol, codeine and morphine are similar in their seizure-inducing potential. ${ }^{17,18}$ Furthermore, increased extracellular concentrations of serotonin appear protective against seizures, ${ }^{2}$ as they may be for antidepressants (see below). These findings suggest that the seizure-inducing effects of tramadol are not mediated through the serotonin pathway. Rather, they, and presumably those of other opioids, may be due to opioid-dependent inhibition of GABAergic pathways ${ }^{18,19}$ or histamine $\mathrm{H}_{1}$-receptor activation. ${ }^{20}$

\section{Non-opioid analgesics}

Non-steroidal anti-inflammatory drugs (NSAIDs) inhibit cyclo-oxygenase enzymes, reducing synthesis of prostaglandins from arachidonic acid. The effects of individual prostaglandins vary but, in general, they 
increase the seizure threshold, and NSAIDs accordingly have potential to lower the seizure threshold. ${ }^{21}$ This effect is seen in various models, in a dose-dependent fashion, for aspirin, diclofenac and indometacin, ${ }^{21}$ and there are reports of seizures being caused clinically by these agents during therapeutic use. ${ }^{22,23}$ By contrast, ibuprofen and paracetamol have not been shown to lower the seizure threshold and there is some evidence that they may increase it, perhaps because of differential effects on individual prostaglandin synthesis. ${ }^{24}$ Mefenamic acid has a non-linear dose-response effect on seizure threhold. In animal models, it suppresses seizures at doses of $20-40 \mathrm{mg} / \mathrm{kg}^{24,25}$ whereas at $60 \mathrm{mg} / \mathrm{kg}^{24}$ and in toxicity clinically ${ }^{23}-$ it can induce seizures.

\section{Methylxantines}

The bronchodilator theophylline, and its soluble derivative aminophylline, cause a significant reduction in the seizure threshold in animal models ${ }^{26}$ and in electroconvulsive therapy. ${ }^{27}$ The mechanism has been ascribed to adenosine $A_{1}$-receptor antagonism. ${ }^{26}$ This can lead to seizures in patients with and without epilepsy, which can be intractable. ${ }^{28}$ This may be because methylxanthines also antagonise the actions of benzodiazepines. ${ }^{29}$ Phenytoin is poorly effective and should be avoided. Early use of alternative secondline agents such as phenobarbital, and if necessary induction of general anaesthesia, is advisable.

\section{Antipsychotics}

Clozapine has the most marked effects on the seizure threshold, followed by other second-generation antipsychotics. ${ }^{30,31}$ First-generation antipsychotics have only a modest effect. Clozapine is associated with concentration-dependent electroencephalographic abnormalities and, in practice, seizures affect $3-6 \%$ of clozapine-treated patients. ${ }^{32,33}$ Likewise, seizures are commonly noted in studies of spontaneously reported adverse drug reactions,.$^{34}$ In patients who experience seizures while taking clozapine, the risks of discontinuing therapy will often be considered greater than the risks of continuing it. In these instances, prophylactic antiepileptic therapy should be offered. Valproate is often a good choice as it is well tolerated and has potentially desirable supplementary effects as a mood stabilizer and antimanic agent. ${ }^{35}$

In contrast to most other antipsychotics, aripiprazole does not lower the seizure threshold during use, and may indeed have anticonvulsant properties. ${ }^{30,36}$ However, a rebound pro-convulsant effect may occur on withdrawal. ${ }^{30}$

\section{Antidepressants}

The effect of antidepressants on monoaminergic neurotransmission could plausibly modulate the seizure threshold in either direction. Clinical trial data suggest that most commonly used antidepressants are anticonvulsant. ${ }^{37}$ Moreover, antidepressant therapy appears to be both safe and beneficial in patients with epilepsy and co-morbid depression. ${ }^{38} \mathrm{~A}$ recent systematic review reaffirmed this, finding no evidence for an increase in seizure frequency in association with the therapeutic use of selective serotonin reuptake inhibitors (e.g. citalopram, fluoxetine, sertraline), selective serotonin-noradrenaline reuptake inhibitors (e.g. venlafaxine, duloxetine), the selective monoamine oxidase $A$ inhibitor moclobemide, or the presynaptic alpha 2 -adrenoceptor antagonist mirtazapine. ${ }^{39}$ Among the tricyclic antidepressants (TCAs), only clomipramine was associated with a reduction in seizure threshold in 
therapeutic doses. ${ }^{39}$ In contrast to the clinical trial data, observational studies using large population databases have found an increased risk of seizures in association with most antidepressant drugs. ${ }^{40,41}$ In a recent study of patients not known to have epilepsy, ${ }^{40}$ the risk of seizures was elevated for all antidepressant classes, although low in absolute terms. The conflicting findings from observational and interventional studies have several possible explanations, including differences in population characteristics, duration, and statistical power. It could also be due to residual confounding in the observational studies, arising from the known association between depression and epilepsy. ${ }^{42}$ Another consideration is the potential for different effects at therapeutic versus supra-therapeutic concentrations. ${ }^{39}$ Seizures are common in cases of antidepressant overdose, particularly with venlafaxine and TCAs. ${ }^{43}$ The serotonergic and noradrenergic effects of antidepressants, which predominate at therapeutic doses, probably increase the seizure threshold. ${ }^{44}$ In toxicity, other effects such as inhibition of GABAergic and histaminergic transmission may supervene and account for a net reduction in the seizure threshold. ${ }^{44}$ It seems plausible that overdose (intentional or unintentional) may be more common in practice than in trials, and captured less completely in observational studies, such that these events could account for the excess of seizures observed.

\section{Bupropion}

The atypical antidepressant bupropion, which inhibits reuptake of noradrenaline and dopamine, is now used primarily to aid smoking cessation. It has stimulant effects and a clear dose-dependent relationship with seizure risk. Using a prolonged-release preparation in doses licensed for smoking cessation, overt seizures are uncommon, affecting approximately $0.1 \%$ of patients overall. ${ }^{37}$ However, the implications of a reduction in seizure threshold may be important for individual patients with other susceptibility factors.

\section{Antiepileptics}

The intended therapeutic effect of antiepileptic drugs is to increase the seizure threshold. However, in toxic concentrations, whether through overdose or altered pharmacokinetics, they may paradoxically lower it. Furthermore, some forms of epilepsy can be exacerbated by certain antiepileptic agents. For example, carbamazepine and, to a lesser extent, gabapentin and lamotrigine may exacerbate idiopathic generalised and myoclonic epilepsies. ${ }^{45}$ Benzodiazepines and barbiturates, which have important roles in the management of acute seizures, can similarly induce a paradoxical reduction in seizure threshold when taken chronically. Most often, and most predictably, this occurs on withdrawal. Occasionally, however, it can occur during introduction or continuation of therapy. ${ }^{45}$

\section{Anaesthetics}

The effects of lidocaine on the seizure threshold vary with concentration in a bimodal fashion. At low concentrations ( $0.5-5 \mathrm{mg} / \mathrm{L}$ ), lidocaine suppresses seizure activity, and indeed is moderately effective as a second-line anticonvulsant agent for neonatal seizures. ${ }^{46}$ However, at concentrations exceeding $8 \mathrm{mg} / \mathrm{L}$ it lowers the seizure threshold and, with escalating concentrations, will ultimately induces seizures in most subjects. ${ }^{47}$ Lidocaine-induced seizures are generally brief and self-terminating. Bupivicaine can similarly reduce the seizure threshold in toxicity, although cardiotoxicity is usually the greater concern in these cases. 
Volatile general anaesthetic agents such as sevoflurane can induce clinical and electroencephalographic manifestations of seizure activity at low concentrations, but these are promptly suppressed as the concentration increases. ${ }^{48} \mathrm{~A}$ similar but less pronounced effect is evident with intravenous agents such as propofol and thiopentone which, in higher doses, are a mainstay of treatment for status epilepticus. In keeping with this bimodal dose-response pattern, seizures associated with general anaesthesia most often occur during induction or emergence, when the concentration of the anaesthetic agent is low. ${ }^{49}$ Pre-treatment with a benzodiazepine has been advocated for patients who may be susceptible to these transient effects. ${ }^{49}$

\section{Conclusion}

Many drugs can adversely affect the seizure threshold, although whether this leads to overt seizures depends on the concentration of drug reaching the brain, the susceptibility of the individual to its effects, and how these effects vary over time. In managing patients with epilepsy or other risk factors for seizures, one must be mindful of the potential for medications to lower the seizure threshold, so as not to precipitate avoidable seizures. Likewise, in evaluating patients with seizures, consideration must be given to the seizure-provoking potential of their medications. While their contribution may be small in comparison to other susceptibility factors, the fact that medicines can be stopped or modified according to their risk-benefit balance offers an important route to improving seizure control. 


\section{Table 1: Drugs that lower the seizure threshold}

\begin{tabular}{|c|c|c|}
\hline Class & Examples & Notes \\
\hline \multicolumn{3}{|l|}{ Antimicrobials } \\
\hline Beta-lactams & $\begin{array}{l}\text { Penicillins, cephalosporins } \\
\text { and carbapenems }\end{array}$ & $\begin{array}{l}\text { In the absence of other susceptibility factors, } \\
\text { seizures are rare except in high-dose therapy or } \\
\text { toxic accumulation. }\end{array}$ \\
\hline $\begin{array}{l}\text { Antituberculous } \\
\text { agents }\end{array}$ & Isoniazid & $\begin{array}{l}\text { Seizures are a manifestation of pyridoxal-5- } \\
\text { phosphate deficiency; they respond to pyridoxine } \\
\text { and benzodiazepine treatment. }\end{array}$ \\
\hline Antimalarials & Mefloquine, chloroquine & $\begin{array}{l}\text { Doxycycline and atovaquone/proguanil (Malarone }{ }^{\circledR} \text { ) } \\
\text { are safer options for malaria prophylaxis in people } \\
\text { with epilepsy. }\end{array}$ \\
\hline \multicolumn{3}{|l|}{ Analgesics } \\
\hline Opioid & $\begin{array}{l}\text { Morphine, tramadol, } \\
\text { codeine, pethidine, } \\
\text { fentanyl }\end{array}$ & $\begin{array}{l}\text { Experimental models show inconsistent effects and } \\
\text { non-linear dose-response relationships. However, } \\
\text { all opioids appear capable of lowering the seizure } \\
\text { threshold under certain conditions. }\end{array}$ \\
\hline Non-opioid & $\begin{array}{l}\text { Aspirin, diclofenac, } \\
\text { indomethacin }\end{array}$ & $\begin{array}{l}\text { Paracetamol and ibuprofen do not appear to lower } \\
\text { the seizure threshold. Mefenamic acid has a non- } \\
\text { linear dose-response effect on the seizure } \\
\text { threshold; it is pro-convulsant in toxicity. }\end{array}$ \\
\hline Methylxanthines & $\begin{array}{l}\text { Theophylline, } \\
\text { aminophylline }\end{array}$ & $\begin{array}{l}\text { Thought to be due adenosine } \mathrm{A}_{1} \text {-receptor } \\
\text { antagonism. Benzodiazepines may be poorly } \\
\text { effective; phenytoin is generally ineffective. }\end{array}$ \\
\hline Antipsychotics & $\begin{array}{l}\text { Clozapine and, to a lesser } \\
\text { extent, other } \\
\text { antipsychotics (e.g. } \\
\text { risperidone, olanzapine) }\end{array}$ & $\begin{array}{l}\text { Where clozapine is the only effective option, it may } \\
\text { be appropriate to continue it together with an } \\
\text { antiepileptic agent (e.g. valproate). }\end{array}$ \\
\hline Antidepressants & $\begin{array}{l}\text { Bupropion } \\
\text { Other antidepressants, } \\
\text { particularly tricyclics, in } \\
\text { overdose }\end{array}$ & $\begin{array}{l}\text { Bupropion (used in smoking cessation) is clearly } \\
\text { associated with seizures. Data for other } \\
\text { antidepressants at therapeutic dose are conflicting, } \\
\text { but seizures are a common feature of toxicity. }\end{array}$ \\
\hline Antiepileptics & $\begin{array}{l}\text { Carbamazepine } \\
\text { Benzodiazepines (e.g. } \\
\text { diazepam) on withdrawal } \\
\text { of chronic therapy }\end{array}$ & $\begin{array}{l}\text { Most antiepileptics can induce paradoxical seizures } \\
\text { in overdose. Also, carbamazepine can exacerbate } \\
\text { certain primarily generalised seizure types. } \\
\text { Withdrawal from benzodiazepines invariably lowers } \\
\text { the seizure threshold. }\end{array}$ \\
\hline Anaesthetics & Sevoflurane & $\begin{array}{l}\text { Volatile and intravenous anaesthetics invariably } \\
\text { suppress seizures at therapeutic doses, but may } \\
\text { transiently lower the seizure threshold at sub- } \\
\text { therapeutic doses. }\end{array}$ \\
\hline
\end{tabular}




\section{References}

1. Berg AT, Berkovic SF, Brodie MJ, et al. Revised terminology and concepts for organization of seizures and epilepsies: report of the ILAE Commission on Classification and Terminology, 20052009. Epilepsia 2010;51:676-85.

2. Fujimoto $Y$, Funao $T$, Suehiro $K$, et al. Brain serotonin content regulates the manifestation of tramadol-induced seizures in rats: disparity between tramadol-induced seizure and serotonin syndrome. Anesthesiology 2015;122:178-89.

3. Sugimoto $M$, Uchida I, Mashimo $T$, et al. Evidence for the involvement of $G A B A(A)$ receptor blockade in convulsions induced by cephalosporins. Neuropharmacology 2003;45:304-14.

4. Miller AD, Ball AM, Bookstaver PB, et al. Epileptogenic potential of carbapenem agents: mechanism of action, seizure rates, and clinical considerations. Pharmacotherapy 2011;31:40823.

5. Nau R, Sorgel F, Eiffert H. Penetration of drugs through the blood-cerebrospinal fluid/bloodbrain barrier for treatment of central nervous system infections. Clinical Microbiology Reviews 2010;23:858-83.

6. Sutter R, Ruegg S, Tschudin-Sutter S. Seizures as adverse events of antibiotic drugs: A systematic review. Neurology 2015;85:1332-41.

7. Cannon JP, Lee TA, Clark NM, et al. The risk of seizures among the carbapenems: a metaanalysis. Journal of Antimicrobial Chemotherapy 2014;69:2043-55.

8. Mink S, Muroi C, Seule M, et al. Levetiracetam compared to valproic acid: plasma concentration levels, adverse effects and interactions in aneurysmal subarachnoid hemorrhage. Clinical Neurology and Neurosurgery 2011;113:644-8.

9. Park MK, Lim KS, Kim TE, et al. Reduced valproic acid serum concentrations due to drug interactions with carbapenem antibiotics: overview of 6 cases. Therapeutic Drug Monitoring 2012;34:599-603.

10. Schiemann R, Coulaud JP, Bouchaud O. Seizures after antimalarial medication in previously healthy persons. Journal of Travel Medicine 2000;7:155-6.

11. Nevin RL. Epileptogenic potential of mefloquine chemoprophylaxis: a pathogenic hypothesis. Malaria Journal 2009;8:188.

12. Richens A, Andrews C. Clinical practice: antimalarial prophylaxis in patients with epilepsy [corrected]. Epilepsy Research 2002;51:1-4.

13. Green MA, Halliwell RF. Selective antagonism of the GABA(A) receptor by ciprofloxacin and biphenylacetic acid. British Journal of Pharmacology 1997;122:584-90.

14. Foote $F$, Gale K. Morphine potentiates seizures induced by GABA antagonists and attenuates seizures induced by electroshock in the rat. European Journal of Pharmacology 1983;95:259-64.

15. Lauretti GR, Ahmad I, Pleuvry BJ. The activity of opioid analgesics in seizure models utilizing Nmethyl-DL-aspartic acid, kainic acid, bicuculline and pentylenetetrazole. Neuropharmacology 1994;33:155-60.

16. Thundiyil JG, Kearney TE, Olson KR. Evolving epidemiology of drug-induced seizures reported to a Poison Control Center System. Journal of Medical Toxicology 2007;3:15-9.

17. Raffa RB, Stone DJ, Jr. Unexceptional seizure potential of tramadol or its enantiomers or metabolites in mice. Journal of Pharmacology and Experimental Therapeutics 2008;325:500-6. 
18. Gholami M, Saboory E, Roshan-Milani S. Proconvulsant effects of tramadol and morphine on pentylenetetrazol-induced seizures in adult rats using different routes of administration. Epilepsy \& Behavior 2014;36:90-6.

19. Rehni AK, Singh I, Kumar M. Tramadol-induced seizurogenic effect: a possible role of opioiddependent gamma-aminobutyric acid inhibitory pathway. Basic \& Clinical Pharmacology \& Toxicology 2008;103:262-6.

20. Rehni AK, Singh TG, Singh N, et al. Tramadol-induced seizurogenic effect: a possible role of opioid-dependent histamine H1 receptor activation-linked mechanism. Naunyn-Schmiedeberg's Archives of Pharmacology 2010;381:11-9.

21. Rantala H, Tarkka R, Uhari M. Systematic review of the role of prostaglandins and their synthetase inhibitors with respect to febrile seizures. Epilepsy Research 2001;46:251-7.

22. Sanchez Valiente S. [Myoclonic encephalopathy induced by diclofenac treatment]. Revista de Neurología 1995;23:1226-7.

23. Sanchez-Hernandez MC, Delgado J, Navarro AM, et al. Seizures induced by NSAID. Allergy 1999;54:90-1.

24. Wallenstein MC. Attenuation of penicillin models of epilepsy by nonsteroidal anti-inflammatory drugs. Experimental Neurology 1987;98:152-60.

25. Ikonomidou-Turski C, Cavalheiro EA, Turski L, et al. Differential effects of non-steroidal antiinflammatory drugs on seizures produced by pilocarpine in rats. Brain Research 1988;18:472:285-85.

26. Fukuda $M$, Suzuki $Y$, Hino $H$, et al. Adenosine A1 receptor blockage mediates theophyllineassociated seizures. Epilepsia 2010;51:483-7.

27. Kemp MF, Allard J, Paquet M, et al. Impact of an oral theophylline loading dose preelectroconvulsive therapy: a retrospective study in patients with missed or inadequate seizures. The Journal of ECT 2015;31:37-42.

28. Boison D. Methylxanthines, seizures, and excitotoxicity. Handbook of Experimental Pharmacology 2011:251-66.

29. Yoshikawa H. First-line therapy for theophylline-associated seizures. Acta Neurologica Scandinavica. Supplementum. 2007;186:57-61.

30. Citraro R, Leo A, Aiello R, et al. Comparative analysis of the treatment of chronic antipsychotic drugs on epileptic susceptibility in genetically epilepsy-prone rats. Neurotherapeutics 2015;12:250-62.

31. Lertxundi U, Hernandez R, Medrano J, et al. Antipsychotics and seizures: higher risk with atypicals? Seizure 2013;22:141-3.

32. Asenjo Lobos C, Komossa K, Rummel-Kluge C, et al. Clozapine versus other atypical antipsychotics for schizophrenia. Cochrane Database of Systematic Reviews 2010:CD006633.

33. Grover S, Hazari N, Chakrabarti S, et al. Association of Clozapine with Seizures: A Brief Report Involving 222 Patients Prescribed Clozapine. East Asian Archives of Psychiatry 2015;25:73-8.

34. Kumlien E, Lundberg PO. Seizure risk associated with neuroactive drugs: data from the WHO adverse drug reactions database. Seizure 2010;19:69-73.

35. Varma S, Bishara D, Besag FM, et al. Clozapine-related EEG changes and seizures: dose and plasma-level relationships. Therapeutic Advances in Psychopharmacology 2011;1:47-66. 
36. Shafaroodi $\mathrm{H}$, Oveisi $\mathrm{S}$, Hosseini $\mathrm{M}$, et al. The effect of acute aripiprazole treatment on chemically and electrically induced seizures in mice: The role of nitric oxide. Epilepsy \& Behavior 2015;48:35-40.

37. Alper K, Schwartz KA, Kolts RL, et al. Seizure incidence in psychopharmacological clinical trials: an analysis of Food and Drug Administration (FDA) summary basis of approval reports. Biological Psychiatry 2007;62:345-54.

38. Cardamone L, Salzberg MR, O'Brien TJ, et al. Antidepressant therapy in epilepsy: can treating the comorbidities affect the underlying disorder? British Journal of Pharmacology 2013;168:1531-54.

39. Johannessen Landmark C, Henning O, Johannessen SI. Proconvulsant effects of antidepressants - What is the current evidence? Epilepsy \& Behavior 2016. pii: S1525-5050(16)00050-0. doi: 10.1016/j.yebeh.2016.01.029. [Epub ahead of print]

40. Hill T, Coupland C, Morriss R, et al. Antidepressant use and risk of epilepsy and seizures in people aged 20 to 64 years: cohort study using a primary care database. BMC Psychiatry 2015;15:315.

41. Coupland C, Dhiman P, Morriss R, et al. Antidepressant use and risk of adverse outcomes in older people: population based cohort study. BMJ 2011;343:d4551.

42. Tellez-Zenteno JF, Patten SB, Jette N, et al. Psychiatric comorbidity in epilepsy: a populationbased analysis. Epilepsia 2007;48:2336-44.

43. Whyte IM, Dawson AH, Buckley NA. Relative toxicity of venlafaxine and selective serotonin reuptake inhibitors in overdose compared to tricyclic antidepressants. QJM: An International Journal of Medicine 2003;96:369-74.

44. Jobe PC, Browning RA. The serotonergic and noradrenergic effects of antidepressant drugs are anticonvulsant, not proconvulsant. Epilepsy \& Behavior 2005;7:602-19.

45. Gayatri NA, Livingston JH. Aggravation of epilepsy by anti-epileptic drugs. Developmental Medicine \& Child Neurology 2006;48:394-8.

46. Lundqvist M, Agren J, Hellstrom-Westas L, et al. Efficacy and safety of lidocaine for treatment of neonatal seizures. Acta Paediatrica 2013;102:863-7.

47. DeToledo JC. Lidocaine and seizures. Therapeutic Drug Monitoring 2000;22:320-2.

48. Benish SM, Cascino GD, Warner ME, et al. Effect of general anesthesia in patients with epilepsy: a population-based study. Epilepsy \& Behavior 2010;17:87-9.

49. Voss $L$, Sleigh JW, Barnard JP, et al. The howling cortex: seizures and general anesthetic drugs. Anesthesia and Analgesia 2008;107:1689-703. 